\title{
A Facile One-Pot Solvent-Free Synthesis of 1,2-Dihydro-1-arylnaphtho $[1,2-e][1,3]$ oxazine-3-ones Catalyzed by Wet Cyanuric Chloride
}

\author{
Firouzeh Nemati and Azam Beyzai \\ Departement of Chemistry, Semnan University, Semnan 35131-19111, Iran \\ Correspondence should be addressed to Firouzeh Nemati; fnemati_1350@yahoo.com
}

Received 2 June 2012; Accepted 29 August 2012

Academic Editor: Josefina Pons

Copyright (C) 2013 F. Nemati and A. Beyzai. This is an open access article distributed under the Creative Commons Attribution License, which permits unrestricted use, distribution, and reproduction in any medium, provided the original work is properly cited.

A novel one-pot synthesis of 1,2-dihydro-1-arylnaphtho[1,2-e][1,3] oxazine-3-ones by condensation of a variety of aldehydes with $\beta$-naphthol and urea or thiourea in the presence of wet cyanuric chloride under solvent-free condition has been described. High yields, simple procedure, easy workup, short reaction times, and avoiding the use of organic solvent are the advantages of this green methodology.

\section{Introduction}

The construction of new analogs of bioactive heterocyclic compounds represents a major challenge in synthetic organic and medicinal chemistry [8]. Due to their broad spectrum of biological activities, naphthalene-condensed 1,3-oxazin3-ones have been reported to act as antibacterial agents, such as HIV-1 reverse-transcriptase inhibitors [9]. They have been used as precursors in the preparation of phosphine ligands for asymmetric catalysis [10]. Recently, a few methods for the synthesis of 1,2-dihydro-1-arylnaphtho[1,2e] [1,3] oxazine-3-ones have been reported. Generally they are synthesized by three-component condensation of urea or thiourea with an aldehyde and $\beta$-naphthol, which entails the use of $P$-TSA [3], perchloric acid supported on silica [1], montmorillonite K10 [5], phosphomolybdic acid [6], iodine [2], and nano-copper in PEG-400 [4]. However, in spite of their potential utility, some difficulties still exist, such as expensive or toxic reagents. Therefore, the development of new, simple, and cheap methods for the synthesis of 1,2dihydro-1-arylnaphtho[1,2-e][1,3]oxazine-3-ones is of main importance.

TCT is a solid, nonvolatile, inexpensive, commercially available, and easy-to-handle reagent [11]. It has been utilized for various synthetic transformations [12-14]. It is extremely soluble in organic solvents, which makes it an ideal catalyst for organic synthesis.

In continuation of our investigation of using TCT in organic transformation [15-18], herein we want to report the convenient synthesis of 1,2-dihydro-1-arylnaphtho[1,2e] $[1,3]$ oxazine-3-one derivatives via the one-pot multicomponent condensation reaction of aromatic aldehydes, $\beta$ naphthol, and urea or thiourea. The reaction was realised in the presence of a catalytic amount of wet TCT under solventfree condition (Scheme 1).

Our preliminary experiments focused on the optimization of the most appropriate reaction conditions. So a model study was carried out on the synthesis of 1,2dihydro-1-arylnaphtho[1,2-e][1,3] oxazine-3-one by the condensation of benzaldehyde with $\beta$-naphthol and urea. The best result was obtained in the presence of $10 \mathrm{~mol} \%$ of TCT and 1-2 drops of $\mathrm{H}_{2} \mathrm{O}$ at $150^{\circ} \mathrm{C}$ under solventfree condition. The reaction was completed in 12 minutes and the corresponding 1,2-dihydro-1-phenylnaphtho[1,2e] $[1,3]$ oxazin-3-one was isolated in $80 \%$ yield. A higher amount of the catalyst scale did not improve the yield (Table 1). 
ArCHO<smiles>[X]C([NH3+])[NH3+]</smiles><smiles>Oc1ccc2ccccc2c1</smiles>

$\mathrm{X}=\mathrm{O}, \mathrm{S}$<smiles>ClC(Cl)(Cl)[Ge]</smiles>

2-15 min<smiles></smiles>

80-97\%

SCHEme 1: Condensation of $\beta$-naphthol, aldehydes, and urea or thiourea in the presence of wet CT.

TABLE 1: Optimization of the reaction conditions in synthesis of 1,2-dihydro-1-arylnaphtho[1,2-e][1,3]oxazine-3-one ${ }^{\mathrm{a}}$.

\begin{tabular}{lcccc}
\hline Entry & TCT $(\mathrm{moL} \%)$ & Reaction conditions & Time (min) & Yield (\%) \\
\hline 1 & 10 & EtOH/reflux & 120 & 120 \\
2 & 10 & $\mathrm{H}_{2} \mathrm{O} /$ reflux & 120 & 0 \\
3 & 10 & $\mathrm{CH}_{3} \mathrm{CN} /$ reflux & 60 & 0 \\
4 & 5 & Solvent free $/ 120^{\circ} \mathrm{C}$ & 30 & 84 \\
5 & 5 & Solvent free $/ 150^{\circ} \mathrm{C}$ & 60 & 86 \\
6 & 10 & Solvent free $/ 120^{\circ} \mathrm{C}$ & 12 & 87 \\
7 & 10 & Solvent free $/ 150^{\circ} \mathrm{C}$ & 12 & 85 \\
8 & 15 & Solvent free $/ 150^{\circ} \mathrm{C}$ & 12 & \\
\hline
\end{tabular}

Reaction condition: $\beta$-naphthol $(1 \mathrm{mmol})$, benzaldehyde $(1 \mathrm{mmol})$, urea $(1 \mathrm{mmol})$, TCT $(10 \mathrm{~mol} \%, 0.1 \mathrm{mmol})$ and, water $(1-2$ drops $)$ in solvent-free condition at $150^{\circ} \mathrm{C}$.

TABLE 2: Synthesis of 1,2-dihydro-1-arylnaphtho[1,2-e][1,3] oxazine-3-one derivatives.

\begin{tabular}{|c|c|c|c|c|c|}
\hline Entry $^{\mathrm{a}}$ & $\mathrm{ArCHO}$ & Urea/thiourea & Time (min) & Yield $(\%)^{\mathrm{a}}$ & $\mathrm{Mp}(\text { Lit. })^{\circ} \mathrm{C}$ \\
\hline 1 & $\mathrm{C}_{6} \mathrm{H}_{5}$ & Urea & 12 & 87 & $219-222[1]$ \\
\hline 2 & $4-\mathrm{Br}-\mathrm{C}_{6} \mathrm{H}_{4}$ & Urea & 5 & 89 & $221-223[2]$ \\
\hline 3 & $3-\mathrm{Br}-\mathrm{C}_{6} \mathrm{H}_{4}$ & Urea & 9 & 93 & $230-232[1]$ \\
\hline 4 & $4-\mathrm{MeO}-\mathrm{C}_{6} \mathrm{H}_{4}$ & Urea & 8 & 71 & $185-188[3]$ \\
\hline 5 & $4-\mathrm{NO}_{2}-\mathrm{C}_{6} \mathrm{H}_{4}$ & Urea & 3 & 97 & 206-207 [4] \\
\hline 6 & $3-\mathrm{NO}_{2}-\mathrm{C}_{6} \mathrm{H}_{4}$ & Urea & 2 & 91 & $226-227$ [2] \\
\hline 7 & $4-\mathrm{Me}-\mathrm{C}_{6} \mathrm{H}_{4}$ & Urea & 9 & 82 & $171-173[1]$ \\
\hline 8 & $4-\mathrm{Cl}-\mathrm{C}_{6} \mathrm{H}_{4}$ & Urea & 4 & 77 & $213-215[1]$ \\
\hline 9 & $2-\mathrm{Cl}-\mathrm{C}_{6} \mathrm{H}_{4}$ & Urea & 5 & 79 & $249-251[1]$ \\
\hline 10 & $4-\mathrm{F}-\mathrm{C}_{6} \mathrm{H}_{4}$ & Urea & 5 & 94 & $197-200[5]$ \\
\hline 11 & Cinnamaldehyde & Urea & 14 & 87 & $173-175$ \\
\hline 12 & $\mathrm{C}_{6} \mathrm{H}_{5}$ & Thiourea & 15 & 75 & $179-181$ \\
\hline
\end{tabular}

Isolated yields.

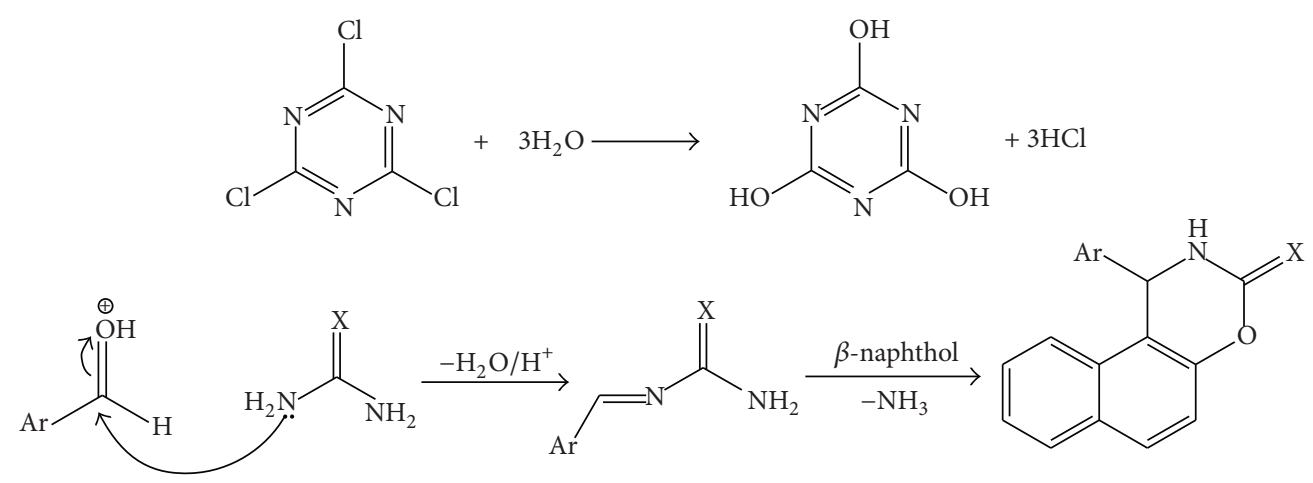

Scheme 2: Plausible mechanism. 
TABLE 3: Comparison of efficiency of various catalysts in synthesis of 1,2-dihydro-1-phenylnaphtho[1,2-e][1,3] oxazin-3-one.

\begin{tabular}{|c|c|c|c|c|c|}
\hline Entry & Condition & $\mathrm{T}^{\circ} \mathrm{C}$ & Time/min. & Yield\% & Reference \\
\hline 1 & Montmorillonite K10 clay/neat & 160 & 30 & 89 & {$[5]$} \\
\hline 2 & $\mathrm{HClO}_{4} / \mathrm{SiO}_{2} /$ neat & 150 & 60 & 85 & {$[1]$} \\
\hline 3 & Phosphomolybdic acid/DMF & 100 & 180 & 87 & {$[6]$} \\
\hline 4 & $\mathrm{I}_{2} /$ Hot plate & 80 & 5 & 96 & {$[2]$} \\
\hline 5 & $P$-TSA ${ }^{\mathrm{a}} /$ neat & 160 & 90 & 58 & {$[3]$} \\
\hline 6 & {$[\mathrm{bmim}] \mathrm{Br} / P$-TSA } & 160 & 180 & 76 & {$[7]$} \\
\hline 7 & Nano $\mathrm{Cu} / \mathrm{PEG}-400$ & $\mathrm{rt}$ & 45 & 93 & {$[4]$} \\
\hline 8 & TCT & 150 & 12 & 87 & This work \\
\hline
\end{tabular}

Results in Table 2 show the generality of this new protocol. The results indicated that the reaction of $\beta$ naphthol with various aromatic aldehydes bearing electronwithdrawing groups (entries 2, 3, 6, 7, 9, 10, and 11), electron-releasing groups (entries 4, 5, and 8), non-aromatic aldehyde (entry 12), and urea or thiourea was afforded in high yields (71\%-97\%) and short reaction times (2-15 minutes) (Table 2).

On the basis of the literature reports $[3,5]$, we have proposed the following plausible mechanism for the formation of 1,2-dihydro-1-arylnaphtho[1,2-e][1,3] oxazine-3-one in the presence of wet TCT (Scheme 2). The TCT reacted with incipient moisture and released 3 moles of $\mathrm{HCl}$ and cyanuric acid as a byproduct [14]. The in situ generated $\mathrm{HCl}$ as a protic acid activated the aldehyde (as indicated in Table 1 , the aldehydes bearing electron withdrawing group needed shorter reaction times as compared to the others). Then an $N$-acylimine intermediate was formed by the reaction of protonated aldehyde with urea or thiourea. The subsequent addition of the $\beta$-naphthol to the $N$-acylimine, followed by the cyclization produces the corresponding products and ammonia. Replacement of $\beta$-naphthol with $\alpha$-naphthol or naphthalene-2-thiol prevented the reaction to proceed.

In Table 3, the efficiency of our method for the synthesis of 1,2-dihydro-1-arylnaphtho[1,2-e][1,3] oxazine-3-one is compared with some other published works in the literature. Each of these methods have their own advantages, but they often suffer from some troubles inclusive of use of organic solvent, high load of catalyst, long reaction time, and employing of expensive catalyst.

In summary, the simplicity of the methodology, ease of the product isolation, very fast and low cost of procedure, high yields, and avoidance of organic solvents could make this process available on an industrial scale.

\section{Experimental}

Chemicals were purchased from the Fluka, Merck, and Aldrich chemical companies. Melting points were determined by an Electrothermal 9100 and are not corrected. TLC on commercial aluminum-backed plates of silica gel 60 F254 was used to monitor the progress of reactions.
${ }^{1} \mathrm{H}$ NMR spectra were recorded on Bruker Avance3 $400 \mathrm{MHz}$ spectrometers in the presence of tetramethyl silan as an internal standard. Elemental analyses were performed by Perkin Elmer CHN analyzer, 2400 series II.

2.1. Typical Procedure for the Synthesis of 1,2-Dihydro1-arylnaphtho[1,2-e][1,3]oxazine-3-ones. A mixture of $\beta$ naphthol $(1 \mathrm{mmol})$, aldehyde $(1 \mathrm{mmol})$, urea or thiourea ( $1 \mathrm{mmol})$, TCT (0.1 mmol, $0.0184 \mathrm{~g})$, and water (1-2 drops) was mixed well and was heated at $150^{\circ} \mathrm{C}$ for an appropriate time (Table 1). After the completion of the reaction (monitored by TLC), the reaction mixture was diluted with $\mathrm{H}_{2} \mathrm{O}$ $(5 \mathrm{~mL})$ and was stirred for 5 minutes. The solid product was filtered and the crude product was crystallized with ethanol to afford the pure product.

\subsection{The Spectral (IR, $\left.{ }^{1} \mathrm{HNMR},{ }^{13} \mathrm{CNMR}\right)$ and Analytical Data for}

1,2-Dihydro-1-styrylnaphtho[1,2-e][1,3]oxazin-3-one (Entry11, Table 2). $\mathrm{mp} 173-175^{\circ} \mathrm{C}$. IR $\left(\mathrm{KBr}, \mathrm{cm}^{-1}\right): 3055,2831,1674$, 1596, 1496, 1396. ${ }^{1} \mathrm{H}$ NMR (400 MHz, DMSO-d 6$): \delta 7.94$ $(1 \mathrm{H}, \mathrm{d}, J=8 \mathrm{~Hz}), 7.88-7.80(4 \mathrm{H}, \mathrm{m}), 7.62(1 \mathrm{H}, \mathrm{t}, J=7.2 \mathrm{~Hz})$, $7.52-7.45(3 \mathrm{H}, \mathrm{m}), 7.42-7.34(2 \mathrm{H}, \mathrm{m}), 5.98(1 \mathrm{H}, \mathrm{t}, J=4 \mathrm{~Hz})$, $3.87(2 \mathrm{H}, d, J=3.6 \mathrm{~Hz}) ;{ }^{13} \mathrm{CNMR}\left(100 \mathrm{MHz}, \mathrm{DMSO}-\mathrm{d}_{6}\right): \delta$ $148.71,147.64,133.93,131.94,130.55,129.00,128.75,128.69$, 127.37, 124.93, 124.55, 123.21, 116.24, 11.57, 97.47, 21.88; Calcd. for $\mathrm{C}_{20} \mathrm{H}_{15} \mathrm{NO}_{2} \mathrm{C}, 79.73 ; \mathrm{H}, 4.98 ; \mathrm{N}, 4.65$; Found: C, $79.81 ; \mathrm{H}, 4.91 ; \mathrm{N}, 4.53$.

\section{1,2-Dihydro-1-phenylnaphtho[1,2-e] [1,3]pxazine-3-thione} (Entry12, Table 2). mp $179-181^{\circ} \mathrm{C}$. IR $\left(\mathrm{KBr}, \mathrm{cm}^{-1}\right)$ : 3386, 3163, 1627, 1596, 1404, 1172. ${ }^{1} \mathrm{H}$ NMR (400 MHz, DMSO$\left.\mathrm{d}_{6}\right): \delta 8.70(1 \mathrm{H}, \mathrm{d}, J=8.8 \mathrm{~Hz}), 7.94(3 \mathrm{H}, \mathrm{d}, J=8.8 \mathrm{~Hz})$, $7.56-7.62(3 \mathrm{H}, \mathrm{m}), 7.57(1 \mathrm{H}, \mathrm{d}, J=8.8 \mathrm{~Hz}), 7.47(2 \mathrm{H}, \mathrm{t}, J=$ $7.6 \mathrm{~Hz}), 7.15(2 \mathrm{H}, \mathrm{t}, J=7.6 \mathrm{~Hz}), 6.98(1 \mathrm{H}, \mathrm{t}, J=7.6 \mathrm{~Hz}), 6.73$ $(1 \mathrm{H}, \mathrm{s}) .{ }^{13} \mathrm{CNMR}\left(100 \mathrm{MHz}, \mathrm{DMSO}-\mathrm{d}_{6}\right): \delta 148.42,146.04$, $131.35,131.10,129.48,129.07,128.85,128.42,127.42,126.72$, 125.02, 123.90, 118.16, 117.90, 36.93; Calcd. for $\mathrm{C}_{18} \mathrm{H}_{13} \mathrm{NOS}$ C, 74.22; H, 4.46; N, 4.81; Found: C, 74.31; H, 4.32; N, 4.75. 


\section{Acknowledgment}

The authors thank the Department of Chemistry and office of gifted student at Semnan University for their financial support.

\section{References}

[1] H. A. Ahangar, G. H. Mahdavinia, K. Marjani, and A. Hafezian, "A one-pot synthesis of 1,2-Dihydro-1-arylnaphtho[1,2-e] oxazine-3-one derivatives catalyzed by perchloric acid supported on silica ( $\mathrm{HClO} 4 / \mathrm{SiO} 2)$ in the absence of solvent," Journal of the Iranian Chemical Society, vol. 7, no. 3, pp. 770-774, 2010.

[2] A. Nizam and M. A. Pasha, "Iodine-catalyzed, rapid and efficient, one-pot synthesis of 1,2-dihydro-1-arylnaphtho[1,2e] oxazine-3-ones under solvent-free conditions," Synthetic Communications, vol. 40, pp. 2864-2868, 2010.

[3] M. Dabiri, A. S. Delbari, and A. Bazgir, "A novel threecomponent, one-pot synthesis of 1,2-dihydro-1-aryl-naphtho[1,2-e][1,3] oxazine-3-one derivatives under microwaveassisted and thermal solvent-free conditions," Synlett, no. 5, pp. 821-823, 2007.

[4] A. Kumar, A. Saxena, M. Dewan, A. De, and S. Mozumdar, "Recyclable nanoparticulate copper mediated synthesis of naphthoxazinones in PEG-400: a green approach," Tetrahedron Letters, vol. 52, no. 38, pp. 4835-4839, 2011.

[5] S. Kantevari, S. V. N. Vuppalapati, R. Bantu, and L. Nagarapu, "An efficient one-pot three component synthesis of 1,2dihydro-1- arylnaphtho[1,2-e][1,3] oxazine-3-ones using montmorillonite K10 under solvent free conditions," Journal of Heterocyclic Chemistry, vol. 47, no. 2, pp. 313-317, 2010.

[6] A. Chaskar, V. Vyavhare, V. Padalkar, K. Phatangare, and H. Deokar, "An environmentally benign one-pot synthesis of 1,2-dihydro-1-aryl-3H- naphth[1,2-e][1,3] oxazin-3-one derivatives catalysed by phosphomolybdic acid," Journal of the Serbian Chemical Society, vol. 76, no. 1, pp. 21-26, 2011.

[7] M. Dabiri, A. S. Delbari, and A. Bazgir, "A simple and environmentally benign method for the synthesis of naphthoxazin-3one derivatives," Heterocycles, vol. 71, no. 3, pp. 543-548, 2007.

[8] A. S. Girgis, "New 1,3-benzoxazin-2-ones or thiones of molluscicidal activity," Pharmazie, vol. 55, no. 6, pp. 426-428, 2000.

[9] M. Patel, R. J. McHugh, B. C. Cordova et al., "Synthesis and evaluation of benzoxazinones as HIV-1 reverse transcriptase inhibitors. Analogs of Efavirenz (Sustiva(TM))," Bioorganic and Medicinal Chemistry Letters, vol. 9, no. 22, pp. 3221-3224, 1999.

[10] Y. Wang, X. Li, and K. Ding, "Synthesis of a new type of chiral amino phosphine ligands for asymmetric catalysis," Tetrahedron Asymmetry, vol. 13, no. 12, pp. 1291-1297, 2002.

[11] G. V. M. Sharma, J. J. Reddy, P. S. Lakshmi, and P. R. Krishna, "A versatile and practical synthesis of bis(indolyl) methanes/bis(indolyl) glycoconjugates catalyzed by trichloro1,3,5-triazine," Tetrahedron Letters, vol. 45, no. 41, pp. 7729-7732, 2004.

[12] Z.-H Zhang, P. Zhang, S.-H Yang, H. G. Wang, and J. Deng, "Multicomponent, solvent-free synthesis of 12-aryl-8,9,10,12tetrahydrobenzo[a]-xanthen-11-one derivatives catalysed by cyanuric chloride," Journal of Chemical Sciences, vol. 122, no. 3, pp. 427-432, 2010.
[13] W. L. Li, Q. Y. Luo, and F. L. Yan, "Cyanuric chloride-catalyzed synthesis of 10-aryl-6,8-dimethyl-6,10-dihydro-5-oxa-6,8diazaanthra[2,3-d][1,3]dioxole-7,9-diones," Chinese Chemical Letters, vol. 22, no. 7, pp. 811-814, 2011.

[14] H. Tajik, A. Dadras, and S. Aghabeygi, "A facile synthesis of novel optically active R,R-2-(4-(2-(4-(5-chloro-3-halo-pyridin2-yloxy)-phenoxy)-propionyloxy)-phenoxy)-propionic acid esters using cyanuric chloride as potential herbicide," Chinese Chemical Letters, vol. 22, no. 5, pp. 535-538, 2011.

[15] M. A. Bigdeli, M. M. Heravi, F. Nemati, and G. H. Mahdavinia, "Polyethyleneglycol an efficient solvent for stereoselective synthesis of $ß$-amino ketones via direct Mannich reaction," Arkivoc, vol. 2008, no. 13, pp. 243-248, 2008.

[16] F. Nemati and H. Kiani, " $\mathrm{Zn}\left(\mathrm{NO}_{3}\right)_{2} \cdot 6 \mathrm{H}_{2} \mathrm{O} / 2,4$,6-trichloro1,3,5-triazine (TCT) a mild and selective system for nitration of phenols," Chinese Chemical Letters, vol. 21, no. 4, pp. 403-406, 2010.

[17] F. Nemati, M. A. Bigdeli, G. H. Mahdavinia, and H. Kiani, "2,4,6-trichloro[1,3,5]triazine (tct)-catalyzed one-pot mannich-type reaction: three component synthesis of $\beta$-amino carbonyl compounds," Green Chemistry Letters and Reviews, vol. 3, no. 2, pp. 89-92, 2010.

[18] F. Nemati, H. Kiani, and Y. S. Hayeniaz, "Cellulose-supported $\mathrm{Ni}\left(\mathrm{NO}_{3}\right)_{2} \cdot 6 \mathrm{H}_{2} \mathrm{O} / 2,4,6$ - trichloro-1,3,5-triazine (TCT) as a mild, selective, and biodegradable system for nitration of phenols," Synthetic Communications, vol. 41, no. 20, pp. 2985-2992, 2011. 

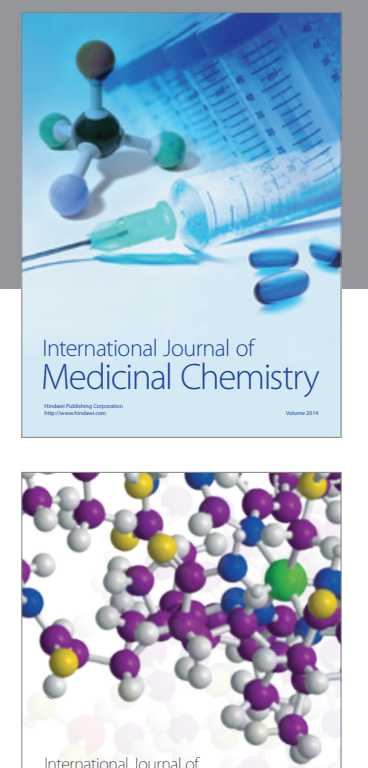

\section{Carbohydrate} Chemistry

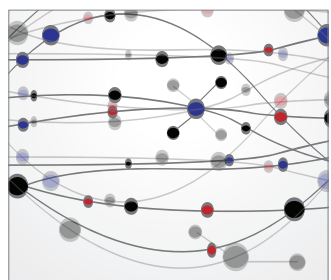

The Scientific World Journal
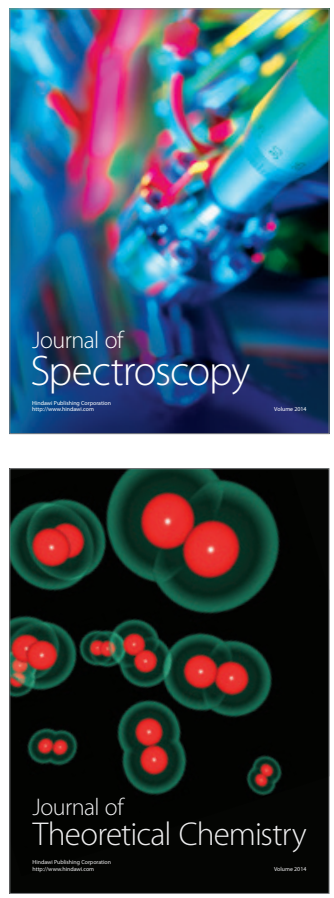
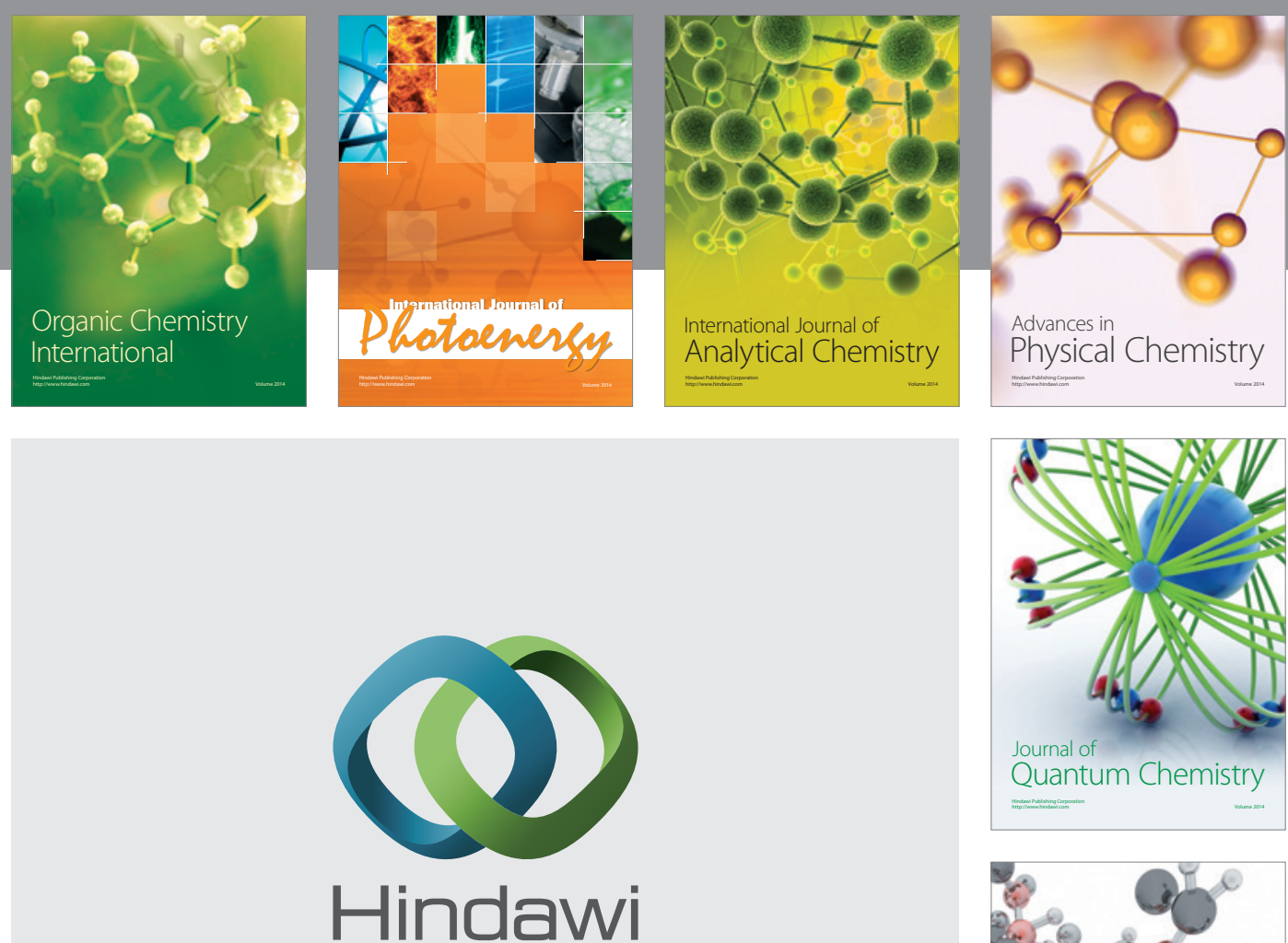

Submit your manuscripts at

http://www.hindawi.com

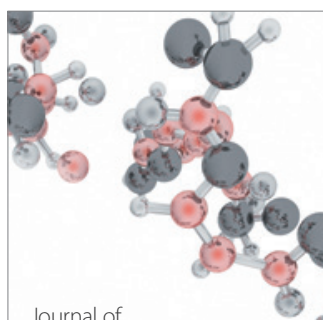

Analytical Methods

in Chemistry

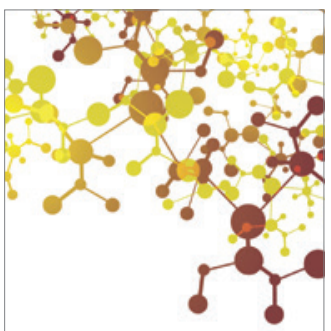

Journal of

Applied Chemistry

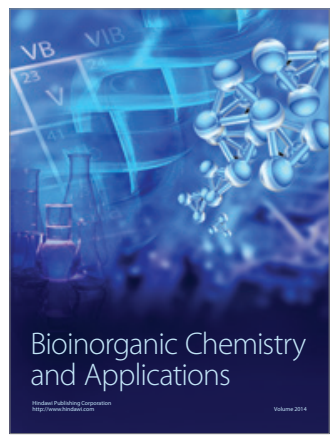

Inorganic Chemistry
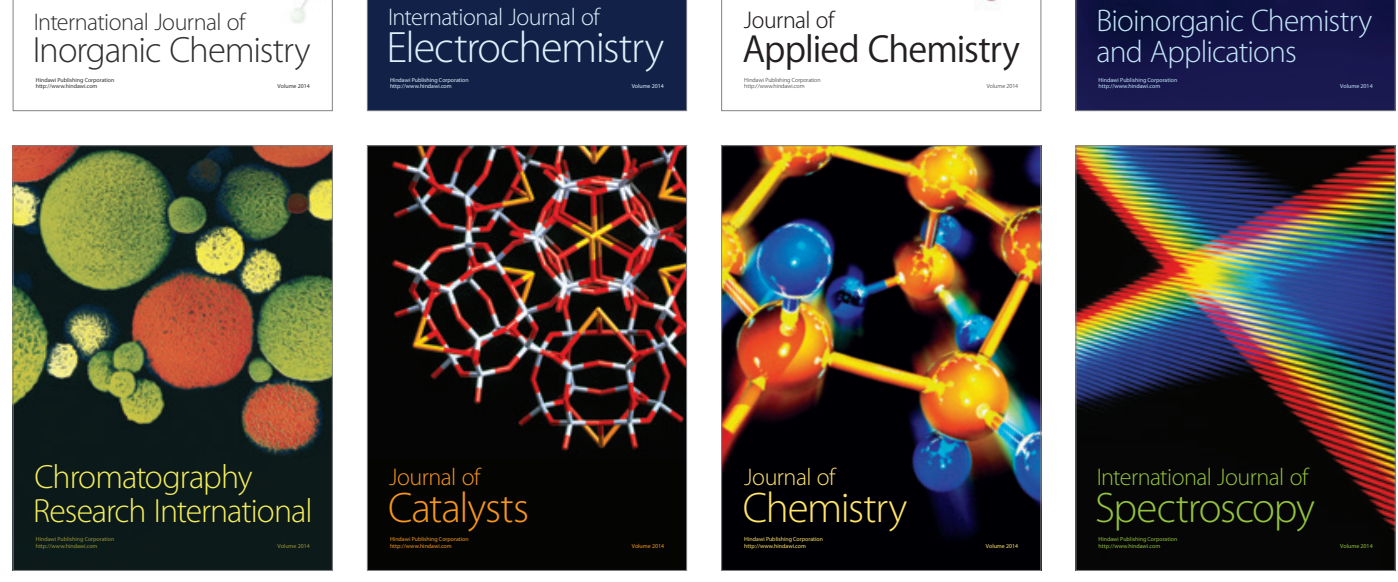